The Psychology of Religion. (Brit. Fourn. of Med. Psychol., March, 1927.) Fones, $E$.

According to Dr. Jones the attributes of power and taboo connected with supernatural beings and the varying emotional attitudes, notably those of dependence, fear, love and reverence, are all direct reproductions of the child's attitude towards his parents. The child's sense of the absolute as expressed in its original preemptive self-regard is, when impaired by contact with reality, partly continued as the anthropocentric view of the universe implicit in all religions, and partly displaced, first on to the parents, and then, when this also fails, on to divine beings. The earthly father is replaced by the Heavenly Father.

The conflicts with the parents lead to repressed death wishes against the parents, with a consequent fear of retaliation, and from this comes the familiar religious impulse to propitiate the spirits of the dead ancestors or other spiritual beings. The accompanying love leads to the desire for forgiveness, reconciliation and succour.

All the emotional problems surrounding death arise, not from the philosophical contemplation of dead strangers, but from the ambivalence towards the person's loved ones. The themes of death and castration are extremely closely associated. The primal selflove and self-importance of the child is displaced on to a selected portion of the mind called the super-ego-an ideal of what the ego longs to be as the result of its moral education.

The sense of inadequacy in coping with life commonly called the inferiority complex takes its origin in the sense of sin or guilt aroused in the child in his endeavour to make all his impulses conform with adult standards. From this the author suggests that all manifestations of inadequacy can be allayed by dealing with their origin by religious means.

G. W. T. H. Fleming.

\title{
5. Pathology.
}

The Endocrines in Epilepsy: A Histological Study. (Brain, March, 1927.) Schon, H. I., and Susman, $W$.

The authors, after reviewing some of the previous results of other workers, examined the endocrine organs in six cases. They found no distinctive lesions in the genital glands. In the thyroid there was a distinct lesion: active degeneration was present in one gland out of four, in another there was a pronounced fibrosis. In the adrenal there was a slow chronic inflammation. The pars glandularis of the pituitary was enlarged in every case and usually to a very pronounced degree. In both the adrenal medulla and the anterior pituitary the destructive agent has a preference for the chromophile cells, producing a similar type of large cell with a very large nucleus, which frequently showed signs of degeneration. In the pancreas there was acinar degeneration, interacinar fibrosis and extremely enlarged islets, i.e., a similar condition to that found in diabetes, but the hypertrophied islets are very much more common 